\title{
Ley 1996 de 2019 \\ Aspectos procesales relacionados con derogatorias, vigencias y régimen de transición
}

Recibido: 30 de septiembre de 2020 • Aprobado: 13 de febrero de 2021
https://doi.org/10.22395/ojum.v20n42a22

\author{
Katherine Andrea Rolong Arias \\ Rama Judicial del Poder Público de Colombia- \\ Juez Primera de Familia de Medellín de Oralidad, Medellín, Colombia \\ krolong@gmail.com \\ https://orcid.org/0000-0002-3340-9860
}

\section{RESUMEN}

Este artículo estudia el régimen de transición de la ley 1996 de 2019 y realiza un análisis del impacto procesal que este conlleva frente a los procesos en curso, terminados y los que pueden ser adelantados, así como en otros procesos jurisdiccionales que se relacionan con este tema. Para ello se realizó un estudio teórico analítico. A partir de lo establecido en la mencionada ley y la jurisprudencia, se analiza la forma en que el nuevo régimen de capacidad genera grandes cambios en el proceso jurisdiccional que requieren de una interpretación ajustada a la Constitución nacional. De esta manera se concluye que, al pasar del régimen de incapacidad al de capacidad, no solo se generó un cambio de paradigma en cuanto a aspectos de naturaleza sustancial, sino que se presentó un gran impacto en las normas de derecho procesal desde el punto de vista de la derogatoria de normas y la entrada en vigencia de otras. Esto se debe a que el procedimiento puede ser iniciado en el régimen de transición. Asimismo, pueden suspenderse los procesos en curso y regular los procesos que se encontraban legalmente terminados para el momento de entrada en vigencia de la ley 1996 de 2019.

Palabras clave: discapacidad; curadurías provisorias; procedimiento de adjudicación de apoyos; suspensión procesal, revisión de sentencia. 


\section{Law 1996 of 2019. Procedural Aspects Related to Repeals, Validities and Regime Transition}

\section{ABSTRACT}

This article aims to address the study of the transition regime of the 1996 law of 2019 and carry out an analysis of the procedural impact that this entails in the face of ongoing processes, those already completed and those that can be advanced, and the impact on other jurisdictional processes related to this issue. For this, an analytical theoretical study was carried out, since, based on what is established in the aforementioned law and jurisprudence, the way in which the new capacity regime generates great changes in the jurisdictional process requires an interpretation adjusted to the National Constitution. To conclude that when moving from the incapacity regime to the capacity regime, not only a paradigm shift was generated in terms of aspects of a substantial nature, but also had a great impact on the procedural law rules from the point of view of repeal of norms, the coming into force of others, regarding the procedure that can be initiated in the transition regime, as well as the suspension of the processes in progress and the regulation of the processes that were legally completed at the time of entry into the validity of the law 1996 of 2019.

Keywords: Disability; provisional curatorships; support award procedure; procedural suspension; sentence review.

\section{Lei 1996 de 2019. Aspectos processuais relacionados com derrogatórias, vigências e sistema de transição}

\section{RESUMO}

Este artigo estudo o sistema de transição da lei 1996 de 2019 e faz uma análises do impacto processual que este implica face aos processos em curso, concluídos e os que podem ser antecipados, assim como outros processos judiciais relacionados ao tema. Para isso se realizou um estudo teórico analítico. A partir do estabelecido na mencionada lei e a jurisprudência, se analisa a nova forma do sistema e a sua capacidade de gerar grandes mudanças no processo jurisdicional que requerem uma interpretação de acordo a Constituição nacional. Dessa maneira, conclui-se que, ao passar do sistema de incapacidade ao de capacidade, não só se deu uma mudança de paradigma enquanto aos aspectos da natureza substancial, se não que apresentou um grande impacto nas normas do direito processual a partir do ponto de vista da derrogatória das normas e a entrada em vigência de outras. Isto deve-se a que o procedimento pode ser começado no sistema de transição. Assim mesmo, podem suspender-se os processos em curso e regular os processos que se encontravam legalmente concluídos para o momento da entrada em vigência da lei 1996 de 2019.

Palavras-chave: Deficiência; curadorias provisórias; apoiar procedimento de concessão; suspensão processual; revisão da frase. 


\section{INTRODUCCIÓN}

Este estudio deriva de la actividad académica con ocasión del desempeño como juez y catedrática. Se empleó un método dogmático porque se analiza la Ley 1996 (2019) en armonía con el Código General del Proceso (2020) y la Constitución Política de Colombia (1991) para determinar el momento a partir del cual se produce la derogatoria de las normas y la vigencia de otras, el impacto que se genera al interior de los procedimientos judiciales, los vacíos e incoherencias que se presentan y la aplicación del régimen de transición a la luz de las instituciones procesales desde su fundamentación filosófica. Para ello se realizó un estudio teórico analítico. En este sentido se analiza, a partir de lo establecido en la Ley 1996 de 2019 y en algunas sentencias de la Corte Constitucional y de la Corte Suprema de Justicia, así como lo que algunos autores han referido al tema desde lo sustancial, la forma en que el nuevo régimen de capacidad genera grandes cambios en el proceso jurisdiccional. Estos requieren de una interpretación ajustada a la Constitución nacional, en particular al principio del debido proceso, como se abordará a continuación.

En Colombia, bajo el esquema de la Ley 1306 (2009), se estaba en un régimen normativo que consideraba incapaces a las personas que eran declaradas en interdicción. Según esta ley, era necesario designarles guardador para que los representara tanto en lo personal como en lo patrimonial. Pero, con la entrada en vigencia de la Ley 1996 (2019), las personas con discapacidad se presumen capaces. Solo en algunas situaciones requieren la adjudicación de un apoyo para la realización de algunos actos jurídicos que deberán estar plenamente determinados. Similar acontecer se presentaba con las personas declaradas con inhabilidad negocial. Se les consideraba incapaces solo para ciertos actos jurídicos, en los que era necesario nombrarles un consejero y, ahora, lo procedente es adjudicarles un apoyo.

Por lo tanto, se puede afirmar que, estando en vigencia el régimen de transición, existen dos de capacidad. El primero se refiere a las personas mayores de edad con discapacidad que no tienen declaración de interdicción o de inhabilidad negocial. En relación con este grupo, existe la presunción de capacidad que pueden requerir o no de adjudicación de apoyo y con las que podría existir o no un proceso en curso para el momento de entrada en vigencia la Ley 1996 (2019). El segundo tiene que ver con las personas incapaces que ya fueron declaradas en interdicción o en inhabilidad negocial para el momento de entrada en vigencia de la ley en comento.

Hay que advertir que este nuevo paradigma conlleva múltiples cambios en aspectos procesales, lo que generará impacto en el régimen definitivo que ha de regir, así como en el de transición que se encuentra ya vigente en los artículos 52 a 56 (Ley 1996, 2019). Estos artículos se encargan de establecer qué procedimiento puede ser iniciado desde ahora en aras de lograr la adjudicación de un apoyo transitorio, el destino de los procesos que se encontraban en curso, encaminados a la declaración de interdicción 
o de inhabilidad negocial, y los que ya se encontraban legalmente terminados con declaraciones en igual sentido.

De esta manera, al expedirse nuevas normas y derogarse otras, se presentan algunas situaciones que deben ser analizadas según el procedimiento de rehabilitación del interdicto, la competencia del juez de familia en primera instancia —al interior del proceso verbal sumario que es de única instancia y además contencioso-y el procedimiento que se le deberá dar a los procesos en curso y terminados en los que la pretensión fue o es prorrogar la patria potestad. Asimismo, se evalúa si en la actualidad es viable o no la designación de guardadores definitivos y provisorios. En cuanto al régimen de transición, este se aplica a las demandas nuevas para la adjudicación de apoyo, a los procesos en curso con solicitud de declaración de interdicción o pretensión de inhabilidad negocial y lo que habrá de presentarse con aquellos que, para el momento de entrada en vigencia la ley, ya tenían sentencia en firme con declaración en tales sentidos.

\section{DEROGATORIAS Y VIGENCIAS MÁS RELEVANTES EN MATERIA PROCESAL CON LA ENTRADA EN VIGENCIA DE LA LEY 1996 DE 2019}

Para abordar este tema es necesario tener en cuenta lo establecido en el artículo 52 de la Ley 1996 (2019) que, en relación con la vigencia de la ley, estableció lo siguiente:

Las disposiciones establecidas en esta ley entrarán en vigencia desde su promulgación, con excepción de aquellos artículos que establezcan un plazo para su implementación y los artículos contenidos en el Capítulo V de la presente ley, los cuales entrarán en vigencia veinticuatro (24) meses después de la promulgación de la presente ley.

Esto quiere decir que, si se está en presencia del régimen de transición, habrá de entenderse que opera desde la promulgación de la ley hasta el momento en que entre en vigencia el régimen procesal de carácter definitivo. Esta vigencia será de veinticuatro meses después de la promulgación de la ley, según lo que se encuentra regulado en el capítulo V. Por lo tanto, desde la promulgación de la ley rige la normativa referente al procedimiento judicial de adjudicación de apoyos transitorios (Ley 1996, 2019, art. 54), mientras que el procedimiento judicial de adjudicación de apoyos definitivo, tanto de jurisdicción contenciosa como voluntaria, entrará a regir veinticuatro meses después de la promulgación de la ley. En relación con los procesos en trámite con solicitud de declaración de interdicción y con pretensión declarativa de inhabilidad negocial, el artículo 55 (Ley 1996, 2019) establece que deben ser suspendidos por el Juez a partir de la entrada en vigencia de la ley, salvo que se soliciten medidas cautelares nominadas e innominadas, tal y como lo desarrolla la Corte Suprema de Justicia en la Sentencia STC-16821/19 (2019). Ahora bien, el artículo 56 de la Ley 1996 (2019) establece que, en relación con los procesos que ya cuentan con sentencia que declaró la interdicción o la inhabilidad negocial, la misma deberá ser revisada y anulada por el juez que las 
profirió dentro de los treinta y seis meses siguientes a la entrada en vigencia del capítulo V. Por lo tanto, serían veinticuatro meses desde la promulgación de la ley para que entre vigencia dicho capítulo y, a partir de ese momento (26 de agosto de 2021), otros treinta y seis meses para que el juez realice la revisión aludida y declare la nulidad de la sentencia. Así, la fecha límite será el 26 de agosto de 2024.

De otro lado, en cuanto a la derogación de normas procesales, se tiene que la Ley 1996 (2019) las estableció en varias normas. De esta manera, el procedimiento de rehabilitación del interdicto, que se encontraba consagrado en el artículo 586 del Código General del Proceso [CGP] (2012), fue derogado por el artículo 37 de la Ley 1996 (2019) al ubicar allí el trámite de adjudicación de apoyos en la toma de decisiones promovido por la persona titular del acto. Asimismo, el artículo 61 derogó el numeral 30 de la Ley 1306 (2009) que igualmente lo regulaba. Empero, es importante precisar que el artículo 37 de la Ley 1996 (2019) se encuentra dentro del capítulo V, el cual solo entrará en vigencia veinticuatro meses después de la promulgación de la ley. Por lo tanto, en la actualidad, el artículo 586 del CGP (2012) se encuentra vigente, lo que conlleva a concluir que se pueden presentar nuevas demandas con esta solicitud y que los procesos que se encuentran en curso deben seguir siendo tramitados. Sin embargo, es importante precisar que cuando entre en vigencia el artículo 37 que derogó el artículo 586 del CGP (2012), ya no podrán iniciarse demandas solicitando la rehabilitación del interdicto. Al parecer, la opción procesal que le quedará a la persona declarada en interdicción consistirá en solicitar el trámite de revisión de la sentencia a partir de la entrada en vigor del régimen procesal de carácter definitivo y en aplicación de lo dispuesto en el artículo 56 (Ley 1996, 2019). Esta situación genera inquietudes. Conforme al artículo 587 del CGP (2012), se señala que no habrá necesidad de citar a ningún interesado en el trámite de rehabilitación del interdicto. El procedimiento aplicable está contemplado en el artículo 586 del CGP (2012), lo que hace que inexorablemente sea de jurisdicción voluntaria, en donde el medio de prueba es el dictamen pericial o el informe técnico. Pero si se revisa el artículo 56, cuando la misma persona titular del acto jurídico es quien acude al juez para que se revise la sentencia, se tiene que:

recibida la solicitud, el juez citará a la persona bajo medida de interdicción o inhabilitación, al igual que a las personas designadas como curadores o consejeros, a que comparezcan ante el juzgado para determinar si requieren de la adjudicación judicial de apoyos. (Ley 1996, 2019)

Por lo tanto, el solicitante y sus guardadores serán citados al proceso sin que se indique en qué calidad. En este escenario, el guardador designado podría oponerse señalando que la persona requiere de apoyos, por lo que tendrá que realizarse el informe de valoración de apoyos al interior de un trámite que ya no será de jurisdicción voluntaria, sino contenciosa. En este contexto, la ley no establece de manera precisa cuál es el trámite por seguir, máxime que en algún momento se determine si el incapaz puede actuar en el proceso independientemente de la actividad del guardador. 
Ahora bien, frente a la competencia del juez de familia en procesos de designación y remoción de guardador, el artículo 61 de la Ley 1996 (2019) derogó los numerales 5 y 6 del artículo 22 del CGP (2012). Este artículo establecía la competencia del juez de familia, en primera instancia, para conocer de la designación, remoción y determinación de la responsabilidad de los guardadores, además de la aprobación de las cuentas rendidas por los guardadores de las personas con discapacidad mental. Frente a esto, habrá de entenderse que si en este momento las sentencias que declararon la interdicción o la inhabilidad negocial siguen surtiendo plenos efectos jurídicos, es conclusión obligada que los guardadores designados siguen cumpliendo sus funciones. ¿Qué sucede entonces cuando se hace necesario nombrar un nuevo guardador ante la muerte del designado o remover un guardador que no está cumpliendo a cabalidad con sus funciones? Si se atiende a la interpretación sistemática que consagra el artículo 30 del Código Civil (2020), se podría concluir que esa derogatoria solo podrá operar cuando quede en firme la sentencia que declara la nulidad de la que declaró la interdicción o la inhabilidad negocial; o bien, y quizás más ajustada a este evento, se hará una aplicación ultraactiva de la norma derogada hasta que se declare la nulidad de la sentencia que declaró la interdicción. De esta manera, el juez de familia podrá conocer los procesos en los que se llegaren a invocar estas pretensiones. Esta aplicación ultraactiva de la norma podría obedecer a que se trata de un tema de competencia específicamente del artículo 46 de la Ley 1306 (2009), que establece un criterio de conexidad con ocasión de la unidad de la actuación. Sin embargo, esta norma también fue derogada por el artículo 61 de la Ley 1996 (2019).

Además, el legislador olvidó que existen otras situaciones que requieren de nombramiento de guardador. Tal es el caso de los menores de edad con padres fallecidos o privados de patria potestad. Se hace necesario nombrarles uno que los represente en los términos de los artículos 53 y 54 de la Ley 1306 (2009), los cuales, dicho sea de paso, no fueron derogados por la Ley 1996 (2019). Así, cuando se trata de estas pretensiones, la competencia ya no se encontraría asignada al juez de familia, por lo que, en principio, la solución estaría dada por la cláusula residual de competencia. Al revisar las normas que al respecto quedaron vigentes de la ley 1306 (2009), se observa que en ellas, no aparece establecida la competencia al juez de esta especialidad. A lo sumo se menciona que se aplicará el Código de Infancia y Adolescencia (2006), sin que, por esa remisión, pueda afirmarse que la competencia esté asignada al juez de familia. En este sentido, deberá existir pronunciamiento por parte del legislador, en tanto el artículo 22, específicamente en los numerales 5 y 6 del CGP (2020), no debió haber sido derogado. En este aspecto, algunos podrían sostener que se aplicaría en el Código de Infancia y Adolescencia y, por ende, el juez competente lo será el de familia. Sin embargo, hay que recordar, que en materia de competencia, rige el principio de legalidad. Por lo tanto, para que un juez sea competente en un asunto requiere de norma expresa que así lo establezca. 
Aunado a ello, se observa que se trata de un procedimiento verbal sumario de primera instancia en tanto el artículo 22 del CGP (2020) establece la competencia del juez de familia en primera instancia. También se advierte que el numeral 7 fue modificado por el artículo 35 de la Ley 1996 (2019) al señalar que conocerá "de la adjudicación, modificación y terminación de los apoyos", esto es, puede ser un asunto de jurisdicción voluntaria o de jurisdicción contenciosa. En este último caso se encuentra establecido el procedimiento verbal sumario. Ello implica que se trata de un procedimiento de doble instancia. Esta situación, en sí misma, va en contra de la regla general consistente en que lo es de única. Así, no solo habrá doble instancia no para la sentencia, sino para todas aquellas providencias que son en sí mismas apelables en los términos del artículo 321 del CGP (2020) y demás normas que así lo establezcan. Si se mira desde el principio de igualdad, esto conllevaría una ventaja; si el procedimiento que se tramita es de jurisdicción voluntaria, lo será en primera instancia, y si es de jurisdicción contenciosa, con mayor razón deberá. Es importante precisar que si el procedimiento de adjudicación de apoyos es iniciado por el sujeto titular del acto jurídico, será de jurisdicción voluntaria, y si es adelantado por un tercero, será de jurisdicción contenciosa.

El procedimiento de prórroga de patria potestad se encontraba regulado en el artículo 26 de la Ley 1306 (2009) y fue derogado por el artículo 61 de la Ley 1996 (2019). En este sentido, los procesos en los cuales se profirió la sentencia que declaró la prórroga de patria potestad de aquellos que reunían los requisitos para ser declarados en interdicción por ser menores de edad, igualmente deberán ser revisados por el juez para anular la sentencia que prorrogó la patria potestad y determinar si requieren de la adjudicación de un apoyo. De ahí se impone la aplicación del artículo 56 de la Ley 1996 (2019). Igualmente, los procesos que al momento de la vigencia de la ley se encontraban en curso deben ser suspendidos, pues el proceso de prórroga de la patria potestad, en últimas, era uno de interdicción. Sin embargo, se advierte que el legislador no dijo nada en relación con la revisión de la sentencia y la consecuente anulación, de manera expresa, frente a este tipo de proceso dijo. Empero, de la interpretación sistemática de la ley, ha de concluirse que es necesario hacerlo atendiendo a la presunción de capacidad de las personas con discapacidad.

Habrá de decirse que el artículo 42 de la Ley 1996 (2019) estableció el contenido del artículo 587 del CGP (2020) al indicar que esta norma ya no regularía el procedimiento de rehabilitación del interdicto, sino que, en su lugar, regularía el trámite de modificación o terminación de los apoyos adjudicados. Esta indicación se encuentra a tono con la presunción de capacidad de las personas con discapacidad establecida en el artículo 6 de la misma ley, pues deja la puerta abierta para modificar o terminar con la adjudicación del apoyo y establece una legitimación, en causa por activa en la persona titular del acto jurídico, en aquellas que demuestren un interés legítimo y en las que fueren designadas como apoyos. De esta manera, al admitir la solicitud, 
se correrá traslado tanto a la persona titular del acto como a la que fue designada como apoyo. En caso de no presentar oposición, se procederá a resolver, evento en el cual es claro que se trata de un procedimiento de jurisdicción voluntaria. Empero, si se presenta oposición de cualquiera de las personas citadas, será necesario practicar pruebas. En este caso, pareciera que el proceso se torna contencioso y, de ser así, surge la inquietud si deberá tramitarse por la cuerda procesal del verbal sumario. El artículo 38 de la Ley 1996 (2019) regula la adjudicación de apoyos cuando es solicitada por un tercero con interés legítimo en relación con una persona que se encuentra absolutamente imposibilitada para manifestar voluntad y preferencias (el cual no sería el evento) o a través del procedimiento verbal, que es residual. El legislador no se ocupó de este último tema.

\section{ANOTACIONES SOBRE EL PROCEDIMIENTO VERBAL SUMARIO ESTABLECIDO POR EL LEGISLADOR PARA LA ADJUDICACIÓN DE APOYOS TRANSITORIO Y DEFINITIVO}

Según el artículo 32 de la ley 1996 (2019), se cuenta con dos procedimientos: el de jurisdicción contenciosa, que se tramita como verbal sumario en primera instancia, y el de jurisdicción voluntaria. En el primer caso será iniciado por un tercero que cuente con "interés legítimo" y en el segundo por la persona con discapacidad.

En relación con el procedimiento verbal sumario, es importante precisar que es declarativo. Esto quiere decir que parte de la duda procesal y que, al contener pretensión, uno de sus elementos estructurales es el ámbito subjetivo. Este aspecto hace referencia a la existencia de dos sujetos procesales, en calidad de partes demandante y demandada, que se encuentran enfrentadas con ocasión de un conflicto intersubjetivo de intereses. Empero, al leer detenidamente el artículo 38 de la Ley 1996 (2019), es posible afirmar que no existe contención o contienda entre demandante y demandado, porque la demanda no se presenta en contra de la persona con discapacidad, sino en beneficio de ella, lo que permitiría afirmar que podría desdibujarse la naturaleza contenciosa del proceso. Lo que realmente lo convertiría en contencioso sería la oposición de la persona titular del acto jurídico o, eventualmente, cuando la persona que se propone en la demanda como apoyo no es el mismo demandante y se opone a dicha designación.

Además, resulta importante precisar que hablar de procedimiento verbal sumario trae de suyo limitaciones tales como el número de preguntas en el interrogatorio, la improcedencia de la reforma a la demanda y la no procedencia de incidentes. No obstante, el artículo 38 de la Ley 1996 (2019) trae la regulación de un incidente cuando establece que la persona designada como apoyo presenta excusa dentro de los cinco días siguientes a la sentencia, esto es, se niega a aceptar sus obligaciones o alega inhabilidad. 
Se advierte que la reforma a la demanda se encuentra contenida en el artículo 93 del CGP (2020). En ese se estipula la parte general y, por ende, procedente en todo tipo de trámite, salvo disposición en contrario, siempre y cuando se solicite antes del señalamiento de fecha de audiencia inicial. Sin embargo, en el procedimiento verbal sumario está vedada la posibilidad de reformar la demanda, lo cual podría atentar contra el principio de economía procesal e, incluso, contra la misma filosofía de la Ley 1996 (2019). Esta ley fue expedida especialmente para personas con discapacidad que requieren apoyos para realizar actos jurídicos diferentes a los ya reclamados, porque sería necesario iniciar otro procedimiento.

Por lo tanto, bajo los anteriores argumentos, podría afirmarse que este procedimiento puede ser tomado como contencioso porque la ley así lo estableció, incluso por su ubicación en el estatuto procesal. Esto se debe a que hace parte de las disposiciones especiales del procedimiento verbal sumario, mas no porque su misma naturaleza permita así concluirlo.

\section{RÉGIMEN DE TRANSICIÓN DE LA LEY 1996 DE 2019}

El artículo 54 de la Ley 1996 (2019) se encargó de regular el procedimiento judicial de adjudicación de apoyos transitorio. En cuanto a los requisitos se establece que este proceso se adelantará de manera excepcional y que debe cumplirse con dos exigencias. La primera consiste en que se trate de persona que "se encuentre absolutamente imposibilitada para expresar su voluntad y preferencias por cualquier medio" y la segunda se da "siempre que sea necesario para garantizar el ejercicio y la protección de los derechos de la persona titular del acto". En este sentido, podrá afirmarse que estos son requisitos de procesabilidad de la acción. Por ello, no todos los eventos de personas con discapacidad conllevan la posibilidad de adelantar el procedimiento de adjudicación de apoyos transitorio. Esto puede explicarse en el artículo 6 de la Ley 1996 (2019), en el cual se establece una "presunción" de capacidad para todas las personas con discapacidad y en igualdad de condiciones, independientemente si se les asignan o no apoyos (Sentencia STC11864/19, 2019).

De tal suerte, solo podrían acudir a que les sea designado un apoyo transitorio las personas que se encuentran en las condiciones particulares antes descritas. Si bien desde el punto de vista legal se habla de un reconocimiento de capacidad en igualdad de condiciones; desde el punto de vista del régimen de transición se establece una diferenciación en cuanto a la forma en que se manifiesta la discapacidad. En este sentido, las personas que pueden expresar su voluntad y preferencias no se encuentran legitimados para invocar pretensión en aras de adjudicarles un apoyo transitorio de manera judicial en aplicación de este artículo. En principio, esto iría en contravía de lo establecido por la Ley 1346 (2009), por medio de la cual se aprobó 
la Convención Internacional sobre los Derechos de las Personas con Discapacidad (Naciones Unidas, 2006), y la Sentencia C-293 (2010), por medio de la cual se declaró su constitucionalidad.

Por lo tanto, al momento de entrar en vigencia el artículo 54, el grupo de personas con discapacidad que no se encontraban absolutamente imposibilitadas para manifestar voluntad y preferencias, tenían la necesidad de un apoyo. Sin embargo, no era posible para ellas ejercer el derecho de acción. Por otra parte, si no contaban con proceso de interdicción en curso, tampoco les quedaba la alternativa de solicitar una medida cautelar nominada o innominada. De esta manera, quedaron, en principio, desprovistas de un mecanismo judicial de carácter ordinario para que les fuera designado un apoyo. Esta situación perduró así desde el 26 de agosto de 2019 hasta el 31 de enero de 2020, fecha en la que la Corte Suprema de Justicia profirió el Auto AC-253 (2020). En este documento se señaló que es posible adelantar el proceso verbal sumario contenido en el artículo 21 numeral 14 del CGP (2020) cuando no se está en las precisas condiciones del artículo 54 de la Ley 1996 (2019). Esto quiere decir que se requiere de la adjudicación de un apoyo para una persona con discapacidad que puede manifestar voluntad y preferencias.

En el procedimiento de adjudicación de apoyos transitorios es necesario, como medio de prueba, el informe de valoración de apoyos. Según el artículo 11 de la Ley 1996 (2019), este podrá ser elaborado por entidades privadas y públicas. Dentro de las entidades públicas, se señala a las personerías, gobernaciones y alcaldías, por lo que se hace preciso advertir que este informe no es requisito de admisión de la demanda. Esto no solo se debe a un procedimiento declarativo que parte de la duda procesal, sino a la redacción del artículo 37 de la Ley 1996 (2019) en los numerales segundo y tercero al establecer que con la demanda se "podrá" aportar el informe de valoración de apoyos. De esta manera, se concluye que si no es aportado o el allegado es insuficiente a criterio del Juez, podrá ordenarse la realización de este informe a las dependencias antes mencionadas. Pero sí será necesario acreditar con la presentación de la demanda y con otros medios de prueba, como certificados médicos e historias clínicas, que para ese momento la persona se encuentra absolutamente imposibilitada para manifestar su voluntad y preferencias. Este es un requisito para que proceda el ejercicio del derecho de acción en los términos en que fue redactado el artículo 54 de la Ley 1996 (2019).

Ahora bien, en relación con la legitimación en causa, es importante precisar que es ordinaria porque se es titular de la relación sustancial de confianza (con la persona con discapacidad) para invocar pretensión que origine el procedimiento de adjudicación de apoyos transitorio y habrá de entenderse que la tiene quien cuente con un "interés legítimo". Sin embargo, existirán eventos en los que las personas con discapacidad no se encuentren en condiciones de establecer o de exteriorizar que frente a otro sujeto existe una relación de esta clase, como acontece justamente con 
las que durante toda su existencia han estado en imposibilidad absoluta de manifestar su voluntad y preferencias. En estos casos será necesario acudir a otros criterios que permitan legitimar por activa a un tercero. Ante tal realidad, el juez de familia se encontrará llamado a verificar la convivencia, el parentesco y la amistad en aplicación a lo establecido en el mismo artículo 54, inciso 3, de la Ley 1996 (2019). Este será uno de los temas de prueba al interior del proceso, pues el apoyo deberá designarse en razón a que conoce la trayectoria de vida de la persona titular del acto o actos jurídicos. Y es que el legislador estableció que, al tratarse de un tercero con interés legítimo, se está en el escenario de un asunto de jurisdicción contenciosa que habrá de ser adelantado por el procedimiento verbal sumario. Este procedimiento se encuentra consagrado en el artículo 390 del Código General del Proceso (2020) con las particularidades establecidas en la Ley 1996 (2019).

Frente a la legitimación en causa por pasiva, el artículo 54 de la Ley 1996 (2019) establece: "La persona titular del acto jurídico podrá oponerse a la adjudicación judicial de apoyos en cualquier momento del proceso". Inclusive, la norma señala que, en cualquier momento, lo que constituye una novedad en relación con el principio de preclusión, el cual establece las posiciones procesales del demandado en los procesos de naturaleza contenciosa frente a las pretensiones de la demanda, se da dentro del término del traslado que se otorga cuando se notifica el auto admisorio. Esta consagración encuentra explicación en que es posible que, para el momento de presentación de la demanda, se estuviera en las precisas condiciones de imposibilidad absoluta de manifestar la voluntad y preferencias, pero en el transcurso del proceso se tuviere algún tipo de mejoría o recuperación que le permita expresarse. Por ello, el legislador optó por dejar la puerta abierta para que pueda oponerse en cualquier estado del proceso. Así, se privilegió la presunción de capacidad de esa persona y se dejó de lado el principio de preclusión que gobierna el proceso jurisdiccional. Sin embargo, hay que decir que el procedimiento se inicia en favor de la persona con discapacidad y no en contra de ella, situación que lo desnaturaliza como de jurisdicción contenciosa. Se tiene, además, que todas las personas que se mencionan como posibles apoyos deberán ser citadas en calidad de demandadas, según lo establece el numeral 5 del artículo 38 que regula el procedimiento de adjudicación de apoyos para la toma de decisiones promovida por persona distinta al titular del acto jurídico: "Antes de la audiencia inicial, se ordenará notificar a las personas identificadas en la demanda y en el informe de valoración de apoyos como personas de apoyo". Esta norma se encuentra dentro del capítulo V, por lo que no ha entrado en vigencia. Empero, como la norma regulará el procedimiento verbal sumario de adjudicación de apoyos que ha de operar de manera definitiva, es perfectamente aplicable al procedimiento de adjudicación de apoyos transitorio en lo no regulado de manera específica por analogía. Se advierte que el Ministerio Público deberá ser notificado del auto admisorio de la demanda en aplicación analógica del numeral 6 del artículo 37 de la Ley 1996 (2019), que regula 
el procedimiento de adjudicación de apoyos definitivo cuando es adelantado por la persona con discapacidad titular del acto. Entenderlo de esta manera tiene su razón de ser en que si el Ministerio Público debe estar vinculado por pasiva cuando la misma persona es quien presenta solicitud de adjudicación de apoyo transitorio, con mayor razón se hace necesaria su presencia cuando la pretensión es invocada por un tercero que aduce tener un "interés legítimo".

Otro aspecto que debe analizarse es que si la persona titular del acto o actos jurídicos no puede comparecer directamente al proceso, le debe ser garantizado el derecho de acceso a la jurisdicción, como contenido del debido proceso, a través de la designación de un curador ad litem. Al respecto, se hace la claridad, que, vencido el término del traslado a fin de ejercer el derecho de defensa, el curador podrá informar en cualquier momento sobre la mejoría que pueda presentar la persona a la cual representa y, por ende, presentar oposición a que le sea designado apoyo.

La otra opción será designarle un defensor personal (Ley 1996, 2019, art. 14). Si se establece que puede designarse como apoyo, también podría pensarse en un defensor público de la Defensoría del Pueblo para que asuma la representación judicial de la persona con discapacidad.

En la parte final del artículo 54 de la Ley 1996 (2019) se establece que la sentencia que se profiera dentro del procedimiento de adjudicación de apoyos deberá establecer quién o quiénes serán los apoyos, el alcance de los apoyos y la duración de los mismos. Esta situación genera implicaciones frente al principio de congruencia, porque el juez de familia deberá pronunciarse de manera precisa sobre los eventos que así lo requieren. En este sentido, debe atender a lo pretendido por el demandante. Además, es preciso anotar que la duración de los apoyos no podrá ser superior al término de entrada en vigencia del capítulo V de la Ley 1996 (2019), es decir, el 26 de agosto de 2021. De esto se desprende que no es querer del legislador que los apoyos sean adjudicados por tiempo indefinido, lo que implicará necesariamente que lo relativo a apoyos sea revisado a fin de establecer si ya no se necesitan, deben mantenerse o si deben ser adjudicados para otros asuntos.

Ahora bien, en relación con la regulación normativa de los procedimientos con solicitud de interdicción y pretensión de inhabilidad negocial en curso (Ley 1996, 2019, art. 55), es necesario precisar que esas personas se encuentran amparadas por la presunción de capacidad curso (Ley 1996, 2019, art. 6). Por ello, no resulta viable seguir adelantando los procesos que se encontraban en curso para ese momento, por lo que el juez tendrá que ordenar mediante auto, la suspensión. Hay que decir que el término de suspensión de estos procesos debe determinarse a partir del artículo 52. En este se establecieron las vigencias y, de manera precisa, se señaló que a partir de la promulgación de la ley se cuenta con el término de veinticuatro meses para la implementación del capítulo V. Este capítulo justamente establece los dos procedimientos 
definitivos de adjudicación de apoyos, es decir, el de jurisdicción voluntaria (porque la misma persona solicita la adjudicación del apoyo) y el verbal sumario (porque se trata de un tercero con interés legítimo que invoca la pretensión). En este contexto, podría entenderse que este sería el término por el cual estaría suspendido el proceso, sin que, por ello, se vean afectados derechos como los pensionales. Esto se debe a que las entidades públicas o privadas no pueden exigir que exista declaratoria de interdicción para proceder a realizar los correspondientes pagos (Sentencia C-522/19, 2019).

La finalidad de la suspensión de los procesos en curso halla justificación en la posibilidad de solicitar medidas cautelares nominadas e innominadas cuando de la protección de los derechos patrimoniales se trate. En este evento, el legislador retomó lo establecido por el Código General del Proceso (2020):

Cualquier otra medida que el Juez encuentre razonable para la protección del derecho objeto del litigio, impedir su infracción o evitar las consecuencias derivadas de la misma, prevenir daños, hacer cesar los que se hubieren causado o asegurar la efectividad de la pretensión. (art. 590, lit. c)

Habrá de entenderse que, finalizada la suspensión procesal, será necesario determinar si requiere de la adjudicación de apoyos, y se escogerá la vía procesal dependiendo si es un procedimiento de jurisdicción contenciosa o de jurisdicción voluntaria. Además, en vista que el legislador nada dijo sobre lo que sucederá con estos procesos una vez se levante el término de suspensión, se podría pensar en las siguientes soluciones, tanto para los procedimientos con solicitud de interdicción como para los que tienen pretensión de inhabilidad negocial.

Frente a los procesos de interdicción podría plantearse, en primer lugar, que se decrete la terminación del proceso por carencia de objeto. No tendría sentido seguir con el trámite procesal al existir la prohibición establecida en el artículo 53 de la Ley 1996 (2019). Si se necesita la adjudicación de un apoyo, será necesario adelantar un proceso completamente diferente, es decir, de adjudicación de apoyos, bien sea de jurisdicción contenciosa (cuando se trata de un tercero con interés legítimo) o de jurisdicción voluntaria (cuando es la persona titular del acto jurídico quien lo adelanta). Y como en este caso no existe norma de competencia que establezca conexidad, sería necesario que el nuevo proceso sea repartido entre los jueces de familia. Ahora bien, podría pensarse en otra opción, la cual consiste en la readecuación del trámite a fin de obtener, al interior del mismo procedimiento, el pronunciamiento frente a la determinación de la necesidad de adjudicar los apoyos. Esta posición podría tener fundamento en la desaparición de la causal de nulidad de trámite inadecuado que estaba consagrada en el derogado artículo 140 del Código de Procedimiento Civil (1970) e incluso en el mandato que el CGP (2020) le da al juez de adecuar el trámite atendiendo al principio "Jura Novit Curia" (art. 90) del en armonía con el permanente control de legalidad que debe realizarse según lo establecido en el artículo 132 (Código General del Proceso, 2012). 
En relación con los procesos con pretensión de inhabilidad negocial, lo primero que hay que precisar es que se trata de una persona que cuenta con la posibilidad de manifestar voluntad y preferencias. Por lo tanto, será ella la legitimada en causa para presentar solicitud de adjudicación judicial de apoyos a través del procedimiento de jurisdicción voluntaria. Una vez venza el término de suspensión del proceso, no tendrá sentido continuar con el trámite porque el demandante es un tercero que, a voces del CGP (2020), se encontraba legitimado en causa para invocar pretensión de inhabilidad negocial. Pero en el escenario de la Ley 1996 (2019) ya no le estará, porque la solución procesal podría estar dada en la terminación anormal del proceso por carencia de objeto o en la terminación a través de sentencia anticipada ante la falta de legitimación en causa para actuar del demandante (CGP, 2020, art. 278). En este escenario, salvo una eventual solicitud de medidas cautelares nominadas e innominadas, no se halla justificada esta suspensión del proceso con ocasión del régimen de transición. Es importante anotar que esta falta de legitimación en causa por activa no estaría dada para el proceso de inhabilidad negocial que fue adelantado por el mismo inhabilitado, ya que en este caso sería de jurisdicción voluntaria, al igual que el de adjudicación de apoyos (Ley o Código, año, art. 37).

Resulta importante analizar otro aspecto relativo a las curadurías provisorias cuando se trata de procesos en curso que se encuentran suspendidos. Si se parte de la presunción de capacidad legal de las personas con discapacidad y el querer del legislador en cuanto a la suspensión de estos procesos, se impone concluir que la declaración de interdicción provisoria y la designación de curador provisorio no siguen produciendo efectos jurídicos, lo que se ajusta a la derogatoria que hizo el artículo 61 de la Ley 1996 (2019) del artículo 27 de la Ley 1306 (2009) (Sentencia STC-16392/19, 2019 y Sentencia STC-2070/20, 2020).

Ahora bien, el trámite establecido para los procesos se encuentran legalmente terminados con la sentencia que declaró la interdicción o la inhabilidad negocial contenido en el artículo 56 (Ley 1996, 2019). Esta establece que las sentencias por las que se declaró la interdicción y la inhabilidad negocial con el consecuente nombramiento de guardador, que fueron proferidas con anterioridad a la entrada en vigencia de la Ley 1996 (2019), siguen surtiendo los efectos jurídicos hasta que sean revisadas y anuladas por el mismo juez. Dicha revisión se hará dentro de los treinta y seis meses siguientes a la entrada en vigencia del capítulo V. Según el artículo 52, este entrará en vigor veinticuatro meses contados a partir de la promulgación de la ley, es decir, entre el 26 de agosto de 2021 y el 26 de agosto de 2024.

Por lo tanto, el procedimiento estará encaminado a la revisión y a la anulación de la sentencia en firme. No obstante, es un acto procesal válido. De esta manera, deja de surtir efectos jurídicos con ocasión del tránsito de legislación. Además, el juez debe 
pronunciarse sobre los apoyos, bien sea para adjudicarlos a solicitud de parte o de oficio o para determinar que la persona con discapacidad no los necesita.

La posibilidad de que la revisión se dé de manera oficiosa genera cuestionamientos que se relacionan con la aplicación o no del principio de congruencia. Frente a esto, habrá de anticiparse sin mayor dificultad que cuando la adjudicación de apoyo se da a solicitud de parte, se privilegian principios como la autonomía, primacía de la voluntad y preferencias de la persona titular del acto. En este sentido, este principio es perfectamente aplicable en este escenario. Empero, al no mediar solicitud de parte, no es posible aplicar congruencia, por lo que el juez deberá establecer los actos jurídicos frente a los cuales se requiere apoyo en atención a lo que resulte probado en el proceso, es decir, lo que se advierta como necesario para la persona con discapacidad, según los principios de necesidad, valoración y carga de la prueba. En todo caso, el juez deberá privilegiar la voluntad y preferencias de la persona con discapacidad teniendo en cuenta todos los medios de prueba que se recauden y, en particular, el informe de valoración de apoyos que es imprescindible al interior de los procedimientos de adjudicación de apoyos.

Además, la norma en comento señala que, para realizar esa revisión, el juez deberá citar a la persona que fue declarada en interdicción o en inhabilidad negocial con la finalidad de ser escuchada si ello es posible. Asimismo, deberá analizar las personas que fueron designadas como guardadores a fin de establecer si es necesario disponer apoyos, sin que se determine el procedimiento aplicable. Indica la norma que el juez no solamente deberá citar a la persona que fue declarada en interdicción o inhábil negocial, sino a los guardadores que hayan sido designados. En este punto no es necesario que se defina en qué calidad deben ser citados, es decir, pueden ser citados como interesados o como extremo pasivo.

Nótese cómo la norma establece en los anteriores eventos una regla de conexidad que consiste en lo siguiente: el juez declaró que la interdicción y la inhabilidad negocial, deberá conocer el procedimiento de adjudicación de apoyos que surja con ocasión de la revisión que se haga de los procesos ya terminados. En este sentido, establece que, siempre que sea posible, deberán tenerse en cuenta las preferencias y voluntad de la persona que se encuentra bajo medida de interdicción y de inhabilidad negocial.

La persona que fue declarada en interdicción o en inhabilidad negocial so pena de nulidad de la actuación procesal deberá ser citada al trámite de revisión. El artículo 133 del CGP (2020) establece las causales de nulidad procesal y el numeral 8 señala que una de ellas se origina

[c]uando no se practica en legal forma la notificación del auto admisorio de la demanda a personas determinadas, o el emplazamiento de las demás personas aunque sean indeterminadas, que deban ser citadas como partes, o de aquellas que deban suceder en el proceso a cualquiera de las partes, cuando la ley así lo ordena 
o no se cita al Ministerio Público o a cualquier otra persona o entidad que de acuerdo con la ley debió ser citado.

De esta manera, no se trata de una nueva causal de nulidad, sino de una situación que queda subsumida en el numeral mencionado. De suyo, esta causal es saneable y, por ende, podrá ser alegada por la persona que resulte afectada por ella. Dentro de esta causal de nulidad estaría la no citación de la persona con discapacidad, mas no el hecho de que los guardadores no sean citados. Esto se debe a que, a pesar de que ambos deben ser citados, la causal de nulidad solamente se refiere a la no citación de la persona con discapacidad. Por lo tanto, el auto de citación podría entenderse como al admisorio de la demanda en el que deberá otorgarse el correspondiente traslado si se respeta la posición de ser un proceso verbal sumario. En este sentido, la no citación de los guardadores no constituye causal de nulidad dada la taxatividad que gobierna el régimen de las nulidades procesales.

Ahora bien, las personas que serán citadas a comparecer ante el juez para efectos de la revisión de la sentencia de interdicción o de inhabilidad negocial deberán aportar un informe de valoración de apoyos antes de la fecha en que sean citados a audiencia. En el caso de que se presenten varios informes, se deberá tener en cuenta el que más favorable resulte a la persona con discapacidad, es decir, el que más privilegie su autonomía, su voluntad y preferencias (Ley 1996, 2019, art. 5, num. 4).

Una vez se encuentre vencido el período probatorio, se procederá a proferir sentencia en un lenguaje muy claro y fácil de entender para la persona frente a la que se está requiriendo la adjudicación de apoyos. Así, el contenido de la misma estará dado por la adjudicación de los apoyos. Se indicará de manera muy precisa para qué actos o negocios jurídicos se adjudican, quiénes son las personas que se designan como apoyos y se establecerán claramente sus funciones. Además, se deberá anular la sentencia por medio de la cual se declaró la interdicción y la inhabilidad negocial. En consecuencia, la sentencia se oficiará a la Oficina del Registro Civil y su contenido se publicará por aviso en un medio de amplia circulación nacional. Es importante precisar que no se pretende utilizar la comunicación para anular la anotación de la sentencia que se origina la anulación de la misma, como pareciera indicarlo el legislador, sino con la providencia que el juez profiere en aplicación del artículo 56 (Ley 1996, 2019). Empero, podría acontecer que cuando el juez al realice la revisión con ocasión del procedimiento de adjudicación de apoyos, llegue al convencimiento que la persona no los requiere y así lo decidirá. En ambos casos, una vez se anule la sentencia, comenzará a regir un nuevo régimen de capacidad legal para la persona con discapacidad (Ley 1996, 2019, art. 6). 


\section{CONCLUSIONES}

Con las derogatorias que trajo la Ley 1996 (2019) en materia procesal se presentan cuestionamientos en relación con lo que podría suceder con los procesos que tienen solicitud de rehabilitación del interdicto, pretensión de remoción y designación de guardador que requieren ser analizadas desde las instituciones del derecho procesal y a la luz del propósito de la ley en mención. En este sentido, puede afirmarse que es viable adelantar el procedimiento de rehabilitación del interdicto porque la sentencias que así lo declararon siguen surtiendo plenos efectos jurídicos mientras no sean anuladas por el juez en sede de revisión a voces del artículo 56 (Ley 1996 de 2019). Esta justificación es perfectamente aplicable al proceso en el cual se solicita la remoción o la designación de un nuevo guardador para la persona que ya fue declarada en interdicción.

Si bien el mencionado artículo no indica que deberán ser revisados los procesos de prórroga de patria potestad que ya culminaron con sentencia que así la declaró, es necesario concluir que los mismos equivalen a una declaración de interdicción a partir del momento en que el menor adquiere la mayoría de edad, de tal manera que sean sentencias que deberán ser revisada y anuladas. Por otra parte, en relación con los procesos que se encontraban en curso con la misma pretensión, habrá de decirse que opera la suspensión establecida en el artículo 55 (Ley 1996, 2019).

Con la regulación establecida en el régimen de transición, se hace necesario determinar en qué eventos es posible adelantar el procedimiento de adjudicación de apoyos transitorio. Al respecto se concluye que esto solo será posible cuando la persona con discapacidad se encuentre en absoluta imposibilidad de manifestar voluntad y preferencias y, en caso de no estar en estas condiciones, le quedará la posibilidad de invocar tal pretensión al interior del procedimiento verbal sumario (CGP, 2020, art. 21, num. 14).

En el caso de los procesos que se encontraban en curso con pretensión de declaración de inhabilidad negocial y con solicitud de declaración de interdicción, se concluye que la suspensión tiene como finalidad que puedan decretarse medidas cautelares nominadas e innominadas en aras de garantizar los derechos patrimoniales de la persona con discapacidad y que, finalizado el término de suspensión, tendrá la opción de declarar la terminación de este trámite en razón de la carencia de objeto. Esto se debe a que este tipo de pronunciamientos quedaron prohibidos por el artículo 53 de la Ley 1996 (2019). De ser el caso, sería necesario presentar demanda de adjudicación de apoyos reglado por el régimen definitivo establecido en la misma ley. Otra opción sería adecuar el trámite en aras de favorecer el principio de economía procesal. Esta situación no es aplicable al proceso de inhabilidad negocial que es adelantado de manera contenciosa. Según la Ley 1996 (2019), como se trata de personas que pueden manifestar voluntad y preferencias, a persona titular de los actos jurídicos deberá presentar esta solicitud y, por ende, el trámite será de jurisdicción voluntaria. 
Finalmente, el procedimiento verbal sumario establecido en el artículo 38 de la Ley 1996 (2019) no se ajusta a la naturaleza misma de lo que allí acontece, porque la solicitud no se presenta en contra de la persona con discapacidad, sino a favor de ella. Aun así, se le entiende como parte pasiva, lo cual desnaturaliza la contienda que es el requisito de los procesos de jurisdicción contenciosa. Además de estar prohibidos los incidentes en esta clase de procesos, la misma ley en el mencionado artículo señala que es posible adelantarlo cuando el apoyo designado manifiesta no poder aceptar o estar inhabilitado para ello. La imposibilidad de reformar la demanda, aunque en el transcurso del proceso se observe que la persona con discapacidad necesita de la adjudicación de apoyos para otros actos jurídicos diferentes a los relacionados en la demanda, atenta en contra de la economía procesal e, incluso, de la protección que se predica frente a las personas con discapacidad. Estas personas, a pesar de gozar de presunción de capacidad, siguen siendo sujetos de protección especial.

\section{REFERENCIAS}

Asamblea General de las Naciones Unidas. (2006). Convención Internacional sobre los Derechos de las Personas con Discapacidad. Naciones Unidas. https://www.un.org/esa/socdev/enable/documents/tccconvs.pdf

Consejo Nacional Legislativo. (1887, 15 de abril). Ley 57 de 1987. Código Civil de Colombia. Diario Oficial n. ${ }^{0}$ 7019. https://www.suin-juriscol.gov.co/viewDocument.asp?id $=1789030$

Presidente de la República. (1970, 6 de agosto). Decreto 1400 de 1970. Código de Procedimiento Civil Colombiano. Diario Oficial n. ${ }^{\circ}$ 33150. https://www.cvc.gov.co/sites/default/files/Sistema_Gestion_de_ Calidad/Procesos\%20y\%20procedimientos\%20Vigente/Normatividad_Gnl/Decreto\%201400\%20 de\%201970-Ago-06.pdf

Congreso de la República. (2012, 12 de julio). Ley 1564 de 2012. Código General del Proceso. Diario Oficial n. ${ }^{\circ}$ 48.489.http://www.secretariasenado.gov.co/senado/basedoc/ley_1564_2012.html

Congreso de la República. (2006, 8 de noviembre). Ley 1098 de 2006. Código de Infancia y Adolescencia. Diario Oficial n. ${ }^{\circ}$ 46.446. http://www.secretariasenado.gov.co/senado/basedoc/ley_1098_2006.html

Asamblea Nacional Constituyente. (1991, 20 de julio). Constitución Política de Colombia. Gaceta Constitucional n. ${ }^{\circ}$ 116. http://www.secretariasenado.gov.co/index.php/constitucion-politica

Congreso de la República de Colombia. (2009, 5 de junio). Ley 1306 de 2009. Por la cual se dictan normas para la Protección de Personas con Discapacidad Mental y se establece el Régimen de la Representación Legal de Incapaces Emancipados. Diario Oficial n. ${ }^{\circ}$ 43.370. https://www.minsalud.gov.co/sites/rid/Lists/ BibliotecaDigital/RIDE/DE/DIJ/Ley\%201306\%20de\%202009.pdf

Congreso de la República de Colombia. (2019, 26 de agosto). Ley 1996 de 2019. Por medio de la cual se establece el régimen para el ejercicio de la capacidad legal de las personas con discapacidad mayores de edad. Diario Oficial n. ${ }^{\circ}$ 51.057. http://www.secretariasenado.gov.co/senado/basedoc/ley_1996_2019.html

Corte Constitucional (2010, 21 de abril). Sentencia C-293/2010 (Nilson Pinilla Pinilla, M.P.). https:// bit.ly/2NflnjB

Corte Suprema de Justicia (2019, 5 de septiembre). Sentencia STC-11864 (Aroldo Wilson Quiroz Monsalvo, M.P.). https://bit.ly/3jV4VAO 
Corte Suprema de Justicia (2019, 4 de diciembre). Sentencia STC-16392 (Aroldo Wilson Quiroz Monsalvo, M.P.). https://bit.ly/2ZpYqfU

Corte Suprema de Justicia (2019, 12 de diciembre). Sentencia STC-16821 (Aroldo Wilson Quiroz Monsalvo, M.P.). https://bit.ly/3ptssKp

Corte Suprema de Justicia (2020, 31 de enero). Auto AC-253 (Aroldo Wilson Quiroz Monsalvo, M.P.). https://bit.ly/3bcnTzl

Corte Suprema de Justicia (2020, 27 de febrero). Sentencia STC-2070 (Aroldo Wilson Quiroz Monsalvo, M.P.). https://bit.ly/2LUx8Lw 